\title{
EXPLORING TEACHERS' RESEARCH COMPETENCY: INPUTS TO POLICY ENHANCEMENT
}

\author{
Inero Valbuena Ancho \\ College of Graduate Studies and Teacher Education Research \\ Philippine Normal University - Manila, Philippines \\ ancho.iv@pnu.edu.ph \\ Esperanza Diaz - Cruz \\ Department of Education \\ City of San Jose del Monte, Bulacan, Philippines \\ phie_25@yahoo.com.ph \\ Genevie-Abi Mirasol Calimbahin \\ School of Arts, Sciences and Technology \\ The National Teachers College, Manila, Philippines \\ gm.calimbahin@ntc.edu.ph
}

\begin{abstract}
This study aimed to explore current status of teachers' research competence. The respondents of this study were 120 teachers of elementary, junior high school and senior high school in a City Schools Division, province of Bulacan, Philippines. They were asked to complete a survey of general research skills. The research used quantitative method. The results and findings of this study served as bases for policy enhancement. The findings of this study revealed the current status of teacher-respondents regarding their research skills. The findings presented that the overall numerical rating was "fair" which reflected a much serious state about their plight. The prerequisite to successful implementation of research programs for teachers was on the basic assumption that teachers possess the necessary skills to do the task. Also, this was then being enhanced by revisiting teachers' workload. Moreover, the presence of funding programs for teachers' research projects exhibited a positive development in strengthening support for teachers' professional development.
\end{abstract}

Keywords: teachers, policy enhancement, research competence

\section{A. INTRODUCTION}

s the academy faces the advent of the $4^{\text {th }}$ Industrial Revolution which is highly driven
by knowledge creation, education is placed at the heart of preparing future
generations to thrive in such environment. Transformation in the contemporary education context is crucial to address the needs of the industrial economy. Competencies are being laid out, enhancing those skills deemed 'obsolete' and challenged by the current era. This economy is being fuelled by professionals dubbed by Sekar (2017) to be noble.

It is true that in the coming days, what would matter most would be one's skill of "learning how to learn." Such skill no longer comes with memorizing and reciting a set of facts, but rather by discovering real-world problems, challenges and collaboratively inventing new and better solutions to them. This skill of knowledge production could be greatly done through research. 
In the academe, while teaching and researching encompass professional work and concerns, the latter suggests innovating ways in order to improve the teaching and learning process. Through research, teachers are able to directly identify issues that confront student learning and eventually device ways to address these problems. Research also serves as a spring board for teachers to innovate on emerging knowledge of content and methods in improving their practices (Mills in Hine, 2013).

In the Philippines, the conduct of research among teachers has sparked discourses concerning their professional development and performance evaluation. Ulla, Barrera, and Acompanado (2017) revealed how teachers positively perceived research in the teaching and learning process. Moreover, Department of Education Order No. 16 (2016) also known as the Basic Education Research Agenda, strengthens teachers' potential of contributing to education reforms and development through educational research. Teachers were in the forefront of the profession are able to determine challenges and problems in the classroom that occur at hand, including issues and dynamic attitudes that students face and exhibit related to the overall learner performance. Furthermore, it also identifies teachers and department's concerns and problems, and recommends solutions based on the results and findings gathered.

\section{B. REVIEW OF LITERATURE}

In the long run, teachers being capable of doing research are envisioned of being empowered, motivated, and eventually confident as they habitually generate new knowledge and skills in improving their teaching practices. Professionally, this could serve as an agent of change and learning through teacher action and reflection (Hollingsworth \& Parr, 2007). This could ultimately lead to further growth, expansion, and development of the Philippines' educational system as it readily faces the challenges of the data-driven, knowledge-driven $21^{\text {st }}$ century education.

However, developing research capacity among teachers in the Philippines has been a plight. There are real struggles towards creating a strong, viable, and consistent production of research in the country. Subahan (2001) identified that changing teachers' attitude towards research is crucial. Insufficient research knowledge and skills, the burden of teaching loads, and lack of financial and moral support from school and other concerned agencies serve as barriers towards achieving the 'teacher-researcher' construct.

Training teachers to do research poses numerous obstacles, particularly in encouraging them to solve emerging classroom problems, more than just for the purpose of job promotions and merit. 'Teachers' heavy workload and other administrative responsibilities also do negatively 
affect their research productivity. This localized problem echoes other existing literature of other countries (Nuqui \& Cruz, 2012). As Thornton (2017) asserted, work at school and home are being attended by teachers for more hours.

From the dilemmas reflected in various literature both in Philippine and in foreign contexts, it could be observed that there seems to be a gap between the agenda of the government and its implementation, and this serves as the very rationale of the study. The development of the research culture impacts teachers' competence in research. It believes that one of the ways in which a sustainable capacity for research could be built is through "a local initiative in cultivating and nurturing a desirable research culture and a supportive environment," despite the resource constraints and other challenges. Apparently, there has to be a synergy between individuals in the school system to sustain efforts. It is a joint effort by the teachers and principals to work hand in hand to "clearly define the set of norms, goals, and values" (Cohen, et al., 2009).

In the Philippine context, despite the efforts of the government in informing its teachers about the importance of research, that is still not the case. There has not been built a sustainable research culture among teachers. Once teachers are uninterested to do research, there seems to be a domino effect on the challenges that confront the education system. Research resources are also scarce, and the government's policies in conducting researches are not thoroughly defined. Efforts should be made on improving the performance of teachers which eventually impacts he entire education system in the country. Strengthening technology improvement and making smarter investments could also aid in improving schools (Duffet \& Farkas, 2014).

With the immense role of research in eventually enhancing teaching and learning processes, its role as a catalyst towards greater knowledge generation, and the necessity of forming a robust research culture among teachers, this study seeks to explore public school teachers' research competence and to trace the gap between the government's reinforcement of their agenda and its implementation. Eventually, as Farah (2017) affirmed, plans for professional development should be anchored on "proven techniques". Teachers' research capacity stems from the concepts and principles of contemporary beliefs, values and practices, preferred future of Filipino school leaders' characteristics. These are then explored according to the following categories: general research skills, and quantitative and qualitative research skills. Consequently, the results and findings of this study will serve as a basis for policy enhancement that would be crafted in the endeavour to bridge the aforementioned gap. 


\section{METHOD}

The respondents of this research were 120 elementary, high school and senior high school classroom teachers in a City Schools Division, province of Bulacan, Philippines. They were asked to complete a survey on general research skills. The method used was quantitative research. Majority of the respondents $(45.15 \%)$ have been in active service for $0-5$ years, while $40.95 \%$ of the 120 have been teaching for 6 to 10 years. 65 (68.25\%) of all the respondents had earned Master of Arts units, while 23.1\% had Bachelor degrees. Only 16.8\% had Master of Arts degrees.

The researchers developed a questionnaire that was eventually validated by experts in the field of teacher education and education research. The assistance of these experts was sought to determine whether the instrument substantially fits the context of the study. The following measures were also employed in the entire process of validation: (1) experts' validation; (2) peer evaluation; and (3) pilot testing.

This research was based on the respondents' perceptions to identify teacher's needs and level of competencies when it came to conduct academic research. Consequently, policy inputs were crafted based on the findings of the study. The teachers completed a survey based on the following aspects: general research skills, quantitative and qualitative research skills. In standardizing the data set, a 5 -point Likert scale $(1=$ poor to $5=$ excellent $)$ was used. From the scale, the respondents were instructed to choose the number that best reflects their skills as a teacher-researcher. The adopted research instrument was delivered and collected manually.

Before the respondents involved in the study, informed consent was sought and voluntarily signed by each teacher. The form consisted of the following information: 1) nature of the study; 2) voluntary participation of the respondents; and 3) information and data gathered will be kept confidential and for academic purposes only. There was no conflict of interest among the proponents of the study and no personal connections were established between the researches and the respondents, thus utmost objectivity was observed.

\section{FINDINGS AND DISCUSSION}

The finding of this research was divided into three parts namely, general research skills, qualitative, and quantitative research skills. Each part extrapolates the thorough analysis of the data gathered using the 5-point Likert scale as its basis of interpretation. 
Table 1. General Research Skills of the Teacher Respondents

\begin{tabular}{|c|c|c|c|}
\hline General Research Skill & $\begin{array}{l}\text { Weighted } \\
\text { Average }\end{array}$ & Classification & Rank \\
\hline 1. Identify research problem & 2.9904 & Fair & 1 \\
\hline 2. Identify variable & 2.8 & Fair & 3 \\
\hline 3. State elements of an introduction & 2.8952 & Fair & 2 \\
\hline 4. State hypothesis & 2.6826 & Fair & 6 \\
\hline 5. Identify research design & 2.5714 & Fair & 10 \\
\hline 6. Choose data gathering instrument & 2.5904 & Fair & 8.5 \\
\hline 7. Identify appropriate statistical test & 2.3142 & Fair & 16 \\
\hline $\begin{array}{l}\text { 8. Choose appropriate scale for quantitative and } \\
\text { qualitative variables }\end{array}$ & 2.7047 & Fair & 4.5 \\
\hline 9. Annotate the review of related literature and studies & 2.6571 & Fair & 7 \\
\hline 10. Apply sampling techniques & 2.5523 & Fair & 12 \\
\hline 11. Formulate conclusion from findings & 2.7047 & Fair & 4.5 \\
\hline 12. Communicating/presenting research findings & 2.5904 & Fair & 8.5 \\
\hline 13. Writing/Reporting research findings & 2.5619 & Fair & 11 \\
\hline $\begin{array}{l}\text { 14. Interpreting secondary data (both quantitative and } \\
\text { qualitative) }\end{array}$ & 2.4285 & Fair & 13 \\
\hline 15. Sourcing and evaluating data for research use & 2.3653 & Fair & 15 \\
\hline 16. Managing those who conduct research & 2.4095 & Fair & 14 \\
\hline Weighted Average & \multicolumn{3}{|c|}{2.6136} \\
\hline
\end{tabular}

The respondents' knowledge of general research skills refers to the basic to advance abilities needed to conduct an empirical study. Above is the table showing the results of the survey done to gauge this skill. Based on the table, it can be seen that all 16 skills fall under the "fair" interpretation, with similar scores.

Moreover, the top 3 skills happen to be the following: identify research problem, identify variable, and state elements of an introduction. This shows that the teacher-respondents have a better understanding on these three. These three are basic skills for a beginning researcher. Thus, its concepts are easy to master and can be easily identified in any research article. However, with an average score of 2.6136, it only shows that the teacher-respondents' general research skills still need improvement.

Table 2. Qualitative Research Skills of the Teacher Respondents

\begin{tabular}{l|c|c|c}
\hline \multicolumn{1}{c|}{ Quantitative Research Skills } & $\begin{array}{c}\text { Weighted } \\
\text { Average }\end{array}$ & Interpretation & Rank \\
\hline Interpreting and applying statistics & 2.3809 & Fair & 1 \\
\hline Analysis of survey data & 2.3619 & Fair & 2 \\
\hline Survey design & 2.3333 & Fair & 4 \\
\hline Sampling & 2.3428 & Fair & 3 \\
\hline
\end{tabular}


The respondents' knowledge of quantitative research skills refers to the ability to handle data and use numerical evidence systematically. These are skills that are generally found in conducting quantitative researches. Table above shows the results of the survey done to gauge this skill. Based on the table, it can be seen that all 4 skills fall under the "fair" interpretation, with similar scores. Moreover, the top 3 skills happen to be the following: interpreting and applying statistics, analysis of survey data, and sampling. This shows that the teacher-respondents have a better understanding of majority of the skills needed for doing quantitative research. Once more, with an average score of 2.3547 , it only shows that the teacher-respondents' quantitative research skills still need improvement.

Table 3. General Qualitative Skills of the Teacher Respondents

\begin{tabular}{l|c|c|c}
\hline \multicolumn{1}{c|}{ Quantitative Research Skills } & $\begin{array}{c}\text { Weighted } \\
\text { Average }\end{array}$ & Interpretation & Rank \\
\hline Qualitative data collection & 2.3428 & Fair & 2.5 \\
\hline Qualitative data analysis & 2.3428 & Fair & 2.5 \\
\hline Actual research writing & 2.666 & Fair & 4 \\
\hline Being able to balance description and interpretation & 2.3619 & Fair & 1 \\
\hline Weighted Average & $\mathbf{2 . 3 2 8 5}$ & \multicolumn{2}{|c}{ Fair } \\
\hline
\end{tabular}

Qualitative research skills refer to the ability of the respondents to analyze and interpret content, trends in thought and opinions, interactions, systems and processes from various sources. These are skills that are generally found in conducting qualitative researches. Above is the table showing the results of the survey done to gauge this skill. Based on the table, it can be seen that all 4 skills fall under the "fair" interpretation, with similar scores. Moreover, the top 3 skills happen to be the following: qualitative data collection, qualitative data analysis, and being able to balance description and interpretation. This shows that the teacher-respondents have a better understanding of majority of the skills needed for doing qualitative research. Nevertheless, with an average score of 2.3285 , it only shows that the teacher-respondents' quantitative research skills still need improvement.

\section{Inputs to Policy Enhancement}

It is without a doubt evident that crafting sound policies to raise the bar of teachers' performance in research could yield favourable outcomes. The policies anchored on concrete and evidence-based viewpoints contribute to successfully developing a culture of research among basic education teachers. Based on the findings of the study, the following inputs to policy enhancement are proposed: 
1. Strengthen pre-service teacher training on research/action research which could be embedded in the teacher education curriculum;

2. Professional education courses may bear research/action research component to enhance pre-service teachers' writing skills'

3. Planning in-service training for teachers may commence with an effective needs analysis study, particularly those specific areas of research that teachers need assistance;

4. Training/seminar/workshop on research writing should not be taken as a one-shot effort. Follow up consultations is crucial to monitor progress and areas that need improvement;

5. Teachers should be given considerable period of time to read, plan, and do research. This should be given attention when designing teacher's program before the start of every school year; and

6. Budgetary allotment on research and training at school level should be made available to teachers. Assistance in logistics and fiscal concerns should also be provided.

While it seems that encouraging school teachers to be engaged in research activities is a challenging feat, data revealed promising findings. The prerequisite to successful implementation of research programs for teachers is on the basic assumption that teachers possess the necessary skills to do the task. Also, this is then being enhanced by providing appropriate funds and revisiting teachers' workload.

\section{E. CONCLUSION}

Findings of the study reveal the current status of teacher-respondents regarding their research skills. While overall numerical rating pegged to be "fair" when interpreted, it reflects a much serious state about their plight. The researchers draw the following conclusion:

1. The challenge of encouraging teachers lies in building the capacity on the basic of research writing;

2. Current research skills of teachers need enhancement in form of sustainable research trainings and programs;

3. More than highlighting support programs for the actual research writing, it is imperative that teachers be equipped with the needed competencies first to be able to conduct research; and

4. Improving the culture of research commences with technically-equipped teachers who possess the know-how of research writing.

The presence of funding programs for teachers' research projects exhibits a positive development in strengthening support for teachers' professional development. This could 
further be enhanced by the provision of regular research writing sessions supervised by experts. Developing the culture of research in the education sector is a promising feat that could yield promising gains which could eventually raise the bar of student achievement. Backed with sound policies and effective research-based programs, making research a part of teacher's everyday life could be made possible.

\section{REFERENCES}

Cohen, J., Mccabe, E. M., Michelli, N. M., \& Pickeral, T. (2009). School climate:research, policy, practice, and teacher education. Teachers College Record, 111(1), 180-123.

Department of Education Order No. 16. (2016). Basic Education Research Agenda.

Duffet, A., \& Farkas S. (2014). Challenges facing principals in the first year at their schools. Universal Journal of Educational Research, 4 , 192-199. Retrieved from http://www.hrpub.org/download/20151231/UJER24-19505300.pdf

Farah, E. (2017). Effective Strategies of a Behavior Management Plan (Master's thesis). Retrieved from Education Commons https: / /www.google.com.ph/url?sa $=\mathrm{t} \& \mathrm{rct}=\mathrm{j} \& \mathrm{q}=\&$ esrc $=\mathrm{s} \&$ source $=$ web\&cd $=$ $1 \& \mathrm{cad}=$ rja\&uact $=8 \&$ ved $=2$ ahUKEwjLxP6YyfLlAhUOzTgGHdgfCuQQFjAAegQI AhAC\&url=https $\% 3 \mathrm{~A} \% 2 \mathrm{~F} \% 2 \mathrm{Fpdfs}$. semanticscholar.org\%2F0880\%2F06ab1e 435175 304cc50d9c8636eeff12188f.pdf\&usg=AOvVaw3UvYWF7tpDDTnyUiJVIbhX.

Hine, G. (2013). The Impotance of Action Research in Teacher Education Programs. Issues in Educational Research 23 (2) Special Issue, 151 - 153.

Nuqiu, A. \& Cruz, R (2012). Determinants of Faculty Research Productivity in Augustinian Higher Education Institutions in Luzon. IAMURE Internation Journal of Education, 3 (1), 1 - 13.

Sekar, R. (2017). Teaching is a Noble Profession. International Journal of Advanced Scientific Research \& Development (IJASRD), bttps:// doi.org/10.26836/ijasrd/2017/v4/i11/4117., 04 (11/I) $54-55$.

Subahan, T. (2001). What Motivates Teachers to Conduct Research? Retrieved from http://www.leeds.ac.uk.

Thornton, M. (2017). Teachers Work too Much and Why You Should Care. Retrieved from medium.com:https://medium.com/@matthew_thornton/teachers-work-too-muchand-why-you-should-care-a1211c13a850

Smith, T. K., Connoly, F., \& Pryseski, C. (2014). Positive school climate: what it looks like and how it happens. Baltimore Education Research Consortium, Retrieved from https:/ / files.eric.ed.gov/fulltext/ED553170.pdf

Ulla, M. Barrera, K., and Acompanado, M. (2017). Philippine Classroom Teachers as Researchers: Teachers' Perceptions, Motivation, and Challenges. Australian Journal of Education, 52 - 64. 